\title{
Dynamics and Considerations in the Determination of the Excretion of Gluten Immunogenic Peptides in Urine: Individual Variability at Low Gluten Intake
}

\author{
Laura Coto $^{1,2}{ }^{(1)}$, Carolina Sousa $^{3}(\mathbb{D})$ and Angel Cebolla ${ }^{1, *(1)}$ \\ 1 Biomedal S.L., 41900 Seville, Spain; laura.coto@biomedal.com \\ 2 Human Nutrition and Food Science Doctoral Program, University of Granada, 18011 Granada, Spain \\ 3 Department of Microbiology and Parasitology, Faculty of Pharmacy, University of Seville, \\ 41012 Seville, Spain; csoumar@us.es \\ * Correspondence: acebolla@biomedal.com; Tel.: +34-955-983-215
}

Citation: Coto, L.; Sousa, C.; Cebolla, A. Dynamics and Considerations in the Determination of the Excretion of Gluten Immunogenic Peptides in Urine: Individual Variability at Low Gluten Intake. Nutrients 2021, 13, 2624. https://doi.org/10.3390/ nu13082624

Academic Editor: Armin Alaedini

Received: 7 July 2021

Accepted: 26 July 2021

Published: 29 July 2021

Publisher's Note: MDPI stays neutral with regard to jurisdictional claims in published maps and institutional affiliations.

Copyright: () 2021 by the authors. Licensee MDPI, Basel, Switzerland. This article is an open access article distributed under the terms and conditions of the Creative Commons Attribution (CC BY) license (https:// creativecommons.org/licenses/by/ $4.0 /)$.

\begin{abstract}
Background: A lifelong strict gluten-free diet is the only available treatment for celiac disease, but total exclusion of gluten is difficult to achieve. The aim of this study was to determine the range of time and the amount of gluten immunogenic peptides (GIP) excreted in urine after specific gluten ingestions. Methods: 20 healthy participants followed the same diet for 12 days in which $50 \mathrm{mg}$ and $2 \mathrm{~g}$ of gluten were ingested and all the urinations were collected. GIP were analyzed by lateral flow immunoassay (LFIA) tests and quantified using an LFIA reader. Results: GIP were detected in $15 \%$ and $95 \%$ of participants after $50 \mathrm{mg}$ and $2 \mathrm{~g}$ gluten intakes, respectively. The higher frequency and concentration of GIP was found between 6 and $9 \mathrm{~h}$ after both gluten ingestions. The ranges of detection were 3-12 h (50 mg) and 0-15 h (2 g). Conclusions: An increase in the frequency of urine tests may be a suitable approach to avoid false negative results. The use of the LFIA test in three urine samples collected at different times may show a sensitivity of $19.6 \%$ for a gluten ingestion like $50 \mathrm{mg}$, increasing to $93 \%$ after 2 g consumption.
\end{abstract}

Keywords: gluten immunogenic peptides; gluten excretion urine; gluten-free diet monitoring; celiac disease

\section{Introduction}

Celiac disease (CD) is a chronic systemic immune-mediated disease triggered by the ingestion of dietary gluten in genetically predisposed individuals with the human leukocyte antigen, HLA-DQ2, and/or HLA-DQ8 haplotypes [1]. The clinical presentation of CD is extremely variable, ranging from typical gastrointestinal symptomatology to extraintestinal symptoms or have no symptoms at all. Importantly, extraintestinal symptoms comprise a substantial proportion of the clinical manifestations of $C D$ such as dermatitis herpetiformis, arthritis, neurological symptoms, anaemia, osteopenia, osteoporosis, tooth enamel defects, aphthous stomatitis, hypertransaminasemia, etc. [1-3]. The pathogenesis of CD involves structural changes in the small intestinal mucosa and intraepithelial lymphocyte infiltration when gluten immunogenic peptides (GIP) resistant to digestive enzymes cross the epithelial barrier to the lamina propria, leading to the activation of both innate and adaptive immune responses [2,4].

Currently, the only treatment available for CD is a lifelong gluten-free diet (GFD). Strict adherence to the GFD is crucial to reverse the clinical manifestations and to prevent long-term complications [1,3,5-7]. However, a diet with the total exclusion of gluten is challenging for most patients, who need high levels of discipline and motivation [1]. Moreover, GFD is more expensive, less palatable, and imposes social constraints, such as when dining out and traveling [8-10]. Consequently, a substantial number of patients with $\mathrm{CD}$, especially those who are asymptomatic, commit diet transgressions and they are at 
risk of developing histological lesions and complications as a result of their condition [11]. The reported rates of GFD adherence range between $12 \%$ and $90 \%$ in adults [11-13] and between $23 \%$ and $98 \%$ in children [14].

Although it has been described in the literature that a daily ingestion of less than $50 \mathrm{mg}$ appears to be safe for most patients with CD [15], other authors have decreased this level to $30 \mathrm{mg}$ to avoid intestinal mucosal abnormalities [16]. As there is a great diversity in gluten sensitivity among individuals [15], the establishment of a harmless threshold of daily gluten intake for the celiac population remains a troublesome task.

Gluten is an alcohol-soluble mixture of storage proteins, known as prolamins, of cereals such as wheat, rye, and barley [17]. These proteins are fundamental for dough formation in bakery products because of their viscoelasticity; however, their applications in the food industry are broader [18]. Wheat gluten prolamins, called gliadins and glutenins, are characterized by being rich in proline and glutamine amino acids, which make them resistant to hydrolysis by gastric and pancreatic enzymes [17]. As a result, an innumerable diversity of GIP is produced in the gastrointestinal tract, triggering an immune response in individuals with $\mathrm{CD}$. In any case, most of the immunogenicity could be assigned to a limited number of gluten epitopes [19]; among the GIP containing the most active T cell epitopes of CD, the $\alpha$-gliadin 33-mer peptide has been described as a paradigm of immunodominance [20].

There is limited evidence regarding gluten digestion, metabolism, and excretion mechanisms. As a dietary protein, gluten hydrolyzation occurs mainly in the small intestine by pancreatic enzymes, which break polypeptides into small peptides and amino acids that are transported through the intestinal barrier [21,22]. Furthermore, it has been described that a fraction of longer peptides resistant to the action of the peptidases can also cross the basolateral membrane of the enterocytes and reach portal circulation [21]. Several authors have reported the detection of GIP in the urine of patients with CD and healthy individuals using mass spectrometry and antibody-based methods [11,13,23-28]. Thus, they demonstrated that gluten-derived peptides enter the kidneys, and after the ultrafiltration process they are partially or totally excreted in the urine. It remains unknown if a proportion of these peptides is also reabsorbed and then metabolized or excreted using alternative pathways.

The use of GIP detection in urine has been developed as a direct test for GFD monitoring in contrast to the classical methods, rather than only detecting the consequences of diet transgressions [11,23]. Urine is an advantageous sample for disease monitoring, as it can be collected fully non-invasively, in large amounts, and repeatedly over long periods of time [29]. Urine is a complex matrix of different components, such as water, glucose, proteins, amino acids, and inorganic salts [29]. However, the usual low concentration of protein in urine and its heterogeneity within and between individuals complicate the determination of the specific moment of analyte excretion [29]. The aim of this study was to determine the individual variability and the dynamics and limit of detection (LoD) of urine GIP excretion after two different amounts of low/moderate gluten ingestion (50 mg and $2 \mathrm{~g}$ ) by monitoring a significant number of participants with minimized diet variations.

\section{Materials and Methods}

\subsection{Study Population}

Between January 2020 and March 2020, 20 healthy volunteers were enrolled from circles of relatives of Biomedal S.L. (Seville, Spain) employees in collaboration with the research group of the University of Seville (Seville, Spain). The criteria for inclusion as healthy volunteers were: (1) participants who were $>18$ years old; (2) not been diagnosed with CD, non-celiac gluten sensitivity, and no food allergies, food intolerances, and other kinds of gastrointestinal diseases; (3) participants who were prepared to follow a strict diet; and (4) to have the determination and abilities for daily urine and stool collection. The exclusion criteria were as follows: (1) participants with associated pathologies or severe 
psychiatric diseases; and (2) participants who did not collect the samples properly on at least $70 \%$ of occasions.

All the subjects provided written informed consent to participate in the study, which was approved by the local ethics committee (n. 2381-N-19).

\subsection{Study Design}

The study involved all participants over a 19-day period. The first week was the wash-out stage, in which the participants had to follow a strict GFD. Two days before the first gluten ingestion, they were asked to collect one sample each of urine and feces to confirm the absence of dietary gluten (Figure 1). After the wash-out period, participants were provided with equivalent gluten-free lunch and dinner menus and gluten-free bread, which were supplied daily by the research team. The meals were consumed within the prescribed GFD. Two doses of gluten (50 $\mathrm{mg}$ and $2 \mathrm{~g}$ ) were ingested in the morning (9:00) on days 8 and 12, respectively, and one sample of all the ordinary individual urinations and depositions (data published separately) were collected during the whole period (12 days in total). From the beginning to the end of the study, a food-recall questionnaire was used to assess GFD adherence and fluid intake, and the participants had to record the name and the quantity of the dishes that they consumed daily.

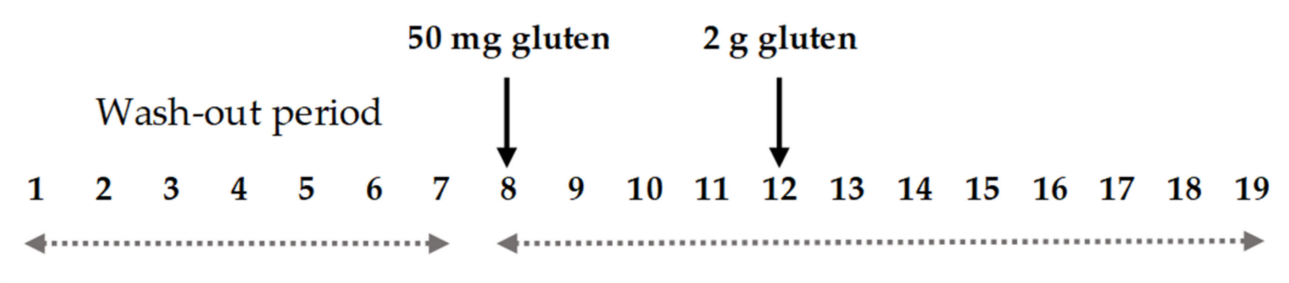

Gluten free diet

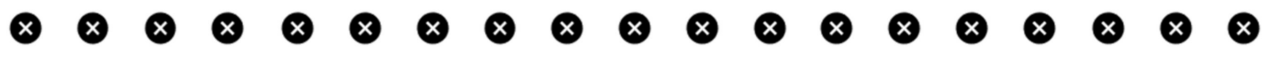

Gluten free precooked meals

Urine and stool collection

Food recall questionnaire

× Performed

GIP negative urine not included for statistical analysis

Urine samples included for statistical analysis

Figure 1. Study timeline.

\subsection{Gluten Administration}

Gluten ingestions consisted of two doses of $50 \mathrm{mg}$ and $2 \mathrm{~g}$ of powdered wheat gluten (El Granero Integral ${ }^{\mathrm{TM}}$; Biogran S.L., Madrid, Spain) encapsulated in "000" size gelatin caps (Your Supplements ${ }^{\mathrm{TM}}$, Bredbury, Stockport, England). The quantity selection was based on the minimum amount of gluten that, when eaten daily, could provoke histological changes in patients with $\mathrm{CD}$ [15] and an amount considered appropriate to observe the dynamic of excretion of GIP in urine. The gelatin caps were analyzed using GlutenTox ${ }^{\circledR}$ ELISA Sandwich kit (Hygiena, Seville, Spain), based on G12 and A1 antibodies, to confirm the absence of gluten. Gluten estimation was calculated by analyzing several samples of maize starch Maizena ${ }^{\mathrm{TM}}$ (Unilever, London, England) spiked with the powdered gluten at different concentrations and analyzed using the GlutenTox ${ }^{\circledR}$ ELISA Sandwich kit (Hygiena, Seville, Spain). Considering the results obtained (near 100\% recovery), gluten doses for each subject were prepared using the total weight of the powdered gluten: $50 \pm 5 \mathrm{mg}$ and $2000 \pm 5 \mathrm{mg}$ in 1 and 4 caps, respectively.

An equivalence calculation of the gluten dosages to bread portions was performed using the methodology described by Biagi et al. [30]. The slice of bread was $11 \mathrm{~cm} \times 12 \mathrm{~cm}$ and weighted $30 \mathrm{~g}$. Based on the nutritional composition given by the manufacturer, the whole slice contained $2.48 \mathrm{~g}$ of gluten. The corresponding amount of gluten in the bread 
slice was $0.6 \mathrm{~g}$ of slice for $50 \mathrm{mg}$ of gluten (Figure $2 \mathrm{a}$ ) and $24 \mathrm{~g}$ for $2 \mathrm{~g}$ of gluten (Figure $2 \mathrm{~b}$ ). A battery (AAA) was used as the standard for size comparison.

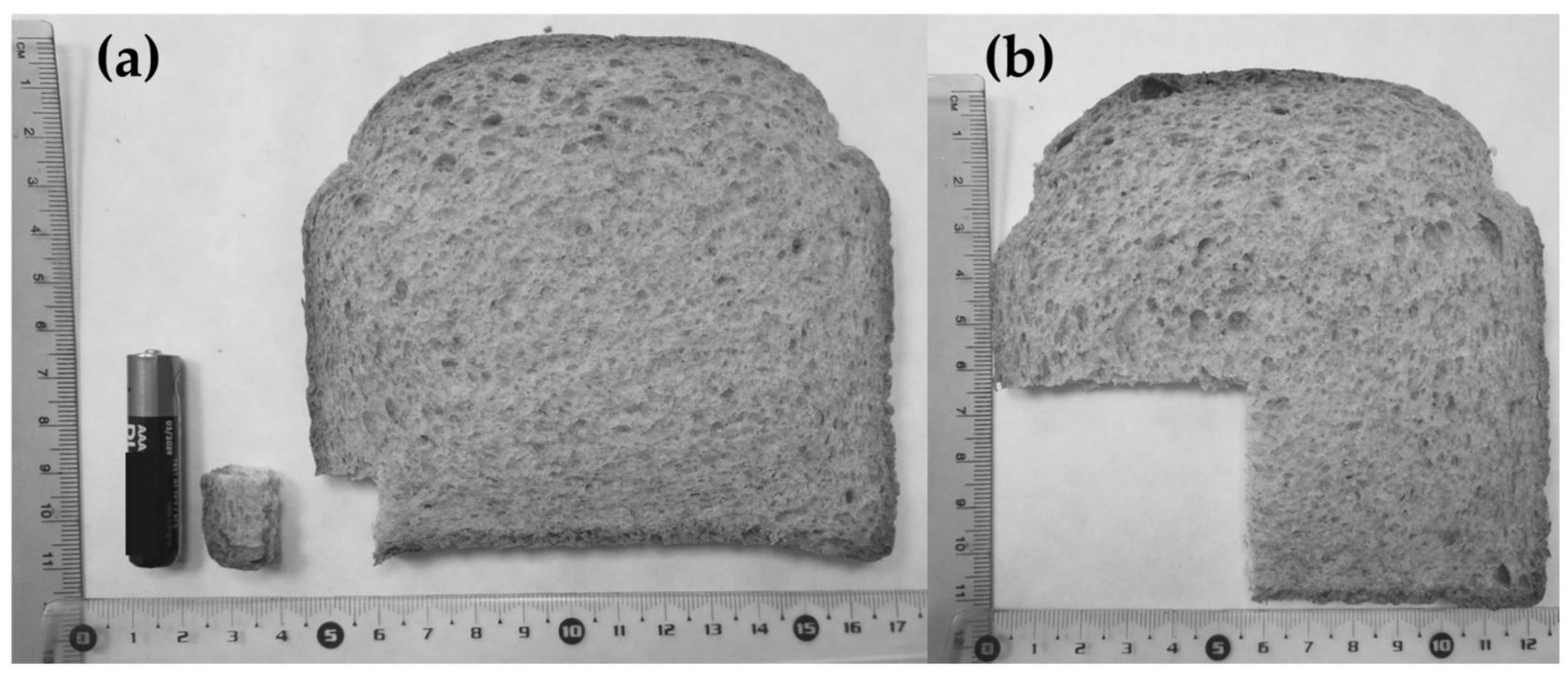

Figure 2. Small piece of bread from the slice representing $50 \mathrm{mg}$ of gluten (a) and slice of bread corresponding to $2 \mathrm{~g}$ of gluten (b).

\subsection{Meal Administration}

All participants followed the same GFD during the gluten excretion period and were provided with ready-to-eat meals for lunch and dinner in addition to gluten-free certified bread (Beiker ${ }^{\mathrm{TM}}$, Dr. Schär, Postal BZ, Italy) to complete meals and for breakfast time. The diet was isocaloric and the ingestion of fresh fruits, unprocessed nuts, and glutenfree beverages was free of choice, depending on the energy requirements and habits of each participant. The meals were ordered from a catering company and were analyzed daily by the ISO17025 certified laboratory services of Biomedal S.L. (Seville, Spain), using GlutenTox ${ }^{\circledR}$ ELISA Sandwich kit (Hygiena, Seville, Spain) to confirm the absence of gluten.

\subsection{Urine Collection}

Detailed instructions were given to all participants at the beginning of the study. The subjects were provided with all materials for urine collection, including specific plastic screw-capped containers, labels, cool bags, isothermal boxes, and cool packs. The participants were instructed to collect between 30 and $60 \mathrm{~mL}$ of each micturition and to write down the date and time of when they pass urine. All urine samples were preserved in isothermal boxes with cool packs at $4-8{ }^{\circ} \mathrm{C}$ and dropped off within $48 \mathrm{~h}$ of collection. All samples were stored at $-20^{\circ} \mathrm{C}$ until processing.

\subsection{Urine Analysis}

GIP qualitative results in urine were measured using a lateral flow immunoassay (LFIA) (iVYCHECK GIP Urine kit, Biomedal S.L., Seville, Spain) following the manufacturer's recommendations. Defrosted urine samples were homogenized and mixed with a conditioning solution. Thereafter, $100 \mu \mathrm{L}$ of the mixture was added to the immunochromatographic cassette and visual interpretation of the results was carried out after $30 \mathrm{~min}$ (recommended time for samples containing a low amount of GIP). A positive result was considered when the test line showed a red color, and the control line showed a green color. A negative result was considered when only the control line showed a green color. The LoD of the technique determined by visual inspection was $2 \mathrm{ng} / \mathrm{mL}$.

The concentration of GIP in urine was also measured in the immunochromatographic strips after $30 \mathrm{~min}$ using the iVYCHECK Reader (Biomedal S.L., Seville, Spain). The validity of this method was previously described by Moreno et al. [23]. The reader was calibrated 
prior to urine analysis using the $\alpha$-gliadin 33-mer peptide as a standard. The measuring range established for this method was: $1.56-25 \mathrm{ng} \mathrm{GIP} / \mathrm{mL}$ urine. The results are expressed as ng GIP per $\mathrm{mL}$ of urine. Each sample was run in duplicate, and at least two different aliquots of each sample were tested.

\subsection{Statistics}

The results of the quantitative variables were expressed using the mean (SD) and median (IQR or range), and those of the categorical variables were expressed as absolute $(\mathrm{N})$ and relative (\%) frequencies. The goodness-of-fit to normality was calculated using the Shapiro-Wilk test. The Mann-Whitney U test was employed to compare quantitative variables in independent groups and for paired quantitative variables, the Wilcoxon test was used.

Only urines not later than $24 \mathrm{~h}$ post gluten ingestion were included for statistical analysis due to later urines from all participants giving a negative result. Ranges of time were established for the study of the dynamics of GIP excretion in intervals of $3 \mathrm{~h}$. All samples from each participant collected in each range were clustered to obtain one result per participant. Any GIP+ sample indicated a total positive result.

Spearman's correlation was used to calculate the association between the liquid consumption after gluten ingestion and the concentration of GIP in urine. Basic probability rules were used to obtain the diagnostic sensitivity of the studied techniques over a predetermined range of time with the different samples collected.

Statistical analyses were performed with IBM SPSS Statistics 25.0 for Windows (IBM Corp, Armonk, NY, USA). Statistical significance was set at $p<0.05$.

\section{Results}

\subsection{Subjects and Samples}

A total of 20 individuals, including 13 (65\%) females and 7 (35\%) males, completed the study after 10 dropouts from the preselection process due to unforeseen events $(n=6)$ and COVID-19 mobility restrictions $(n=4)$. The median age of participants was 30.5 years (IQR 24.7-34.0) (Figure 3).

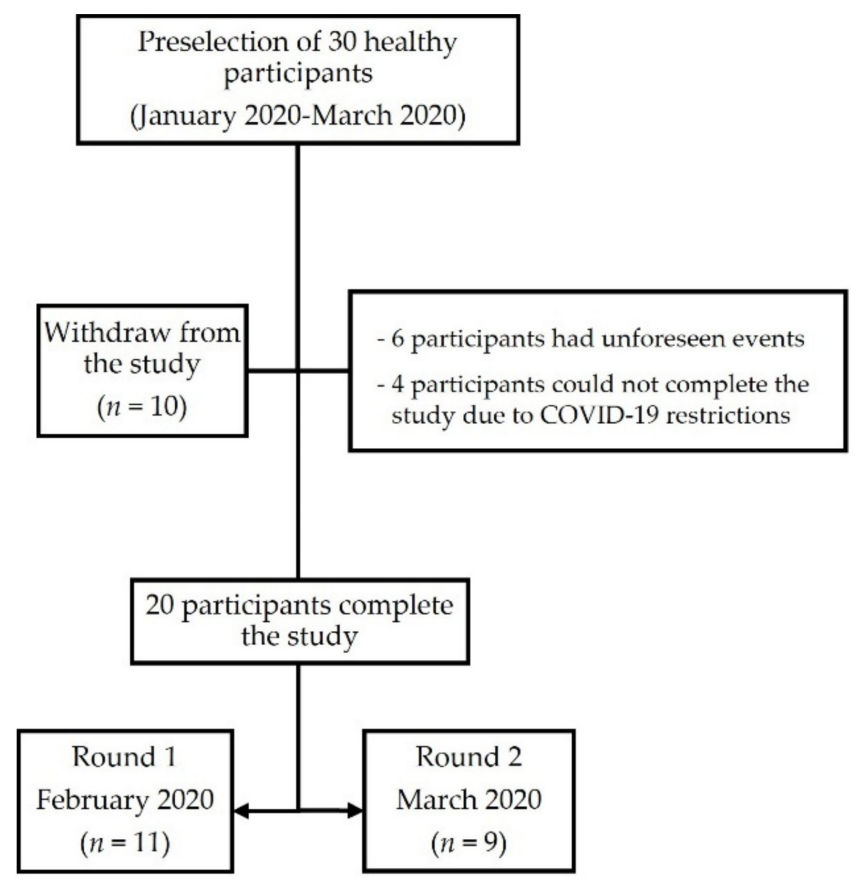

Figure 3. Flowchart of the study participants. 
None of the participants were declared to be diagnosed with a relevant disease or had been taking any probiotics or fiber supplements. One participant reported following a special fitness diet before the study. According to the food-recall completed, all participants were compliant with the prescribed GFD and the gluten dose ingestion. The average fluid intake per participant during the study period was $1.5 \pm 0.6 \mathrm{~L} /$ day.

\subsection{GIP Detection in Urine Samples}

A total of 290 urine samples were collected from all participants during the $24 \mathrm{~h}$ after gluten ingestion, 142 corresponding to the $50 \mathrm{mg}$ gluten dose, and 148 to the $2 \mathrm{~g}$ gluten dose. The remaining samples of the study were excluded for statistical analysis as they obtained GIP negative results. The medians of the number of samples collected per participant in the first $24 \mathrm{~h}$ were 7 (IQR 5-8) for the $50 \mathrm{mg}$ intake and 7 (IQR 5.5-8.5) for the $2 \mathrm{~g}$ intake (Table 1).

GIP were detected in 4/142 (2.8\%) of the urine samples up to $24 \mathrm{~h}$ after $50 \mathrm{mg}$ gluten ingestion, corresponding to $3 / 20(15 \%)$ participants. From these participants, GIP were detected in only one sample for two subjects and in two samples for one subject. Regarding the $2 \mathrm{~g}$ dose, $33.1 \%$ (49/148) of the urine samples were GIP+ during the $24 \mathrm{~h}$ of collection, corresponding to $19 / 20$ (95\%) of the participants. GIP+ samples were obtained in only one to two urinations for $10 / 19$ participants (52.6\%), in three to four urinations for $7 / 19$ participants $(36.8 \%)$, and in five to six urinations for $2 / 19$ participants $(10.5 \%)$.

GIP+ samples were found from the first to the fourth collected samples after $50 \mathrm{mg}$ gluten ingestion. The detection of GIP in urine could be extended up to the eight urinations after the $2 \mathrm{~g}$ dose, with the third sample being where most participants $(16 / 20 ; 80 \%)$ had GIP+ urine.

\subsection{Time Course of GIP Excretion}

GIP were detected in urine samples collected in the first $3 \mathrm{~h}$ after $2 \mathrm{~g}$ gluten intake and between 3-6 h after $50 \mathrm{mg}$ gluten ingestion (Figures 4 and 5). The majority of GIP+ urine samples were found in the range of $6-9 \mathrm{~h}$ after both gluten doses $(18.8 \%$ and $78.8 \%$, respectively) (Figures 4 and 5). As expected, the $2 \mathrm{~g}$ ingestion resulted in significant proportions of positive samples for a longer period ( $3-15 \mathrm{~h}$ ) with rates between $41.2 \%$ and $78.8 \%$ (Figure 5). No positive results were found after $12 \mathrm{~h}$ and $15 \mathrm{~h}$ post ingestion for the $50 \mathrm{mg}$ and the $2 \mathrm{~g}$ doses, respectively (Figures 4 and 5).

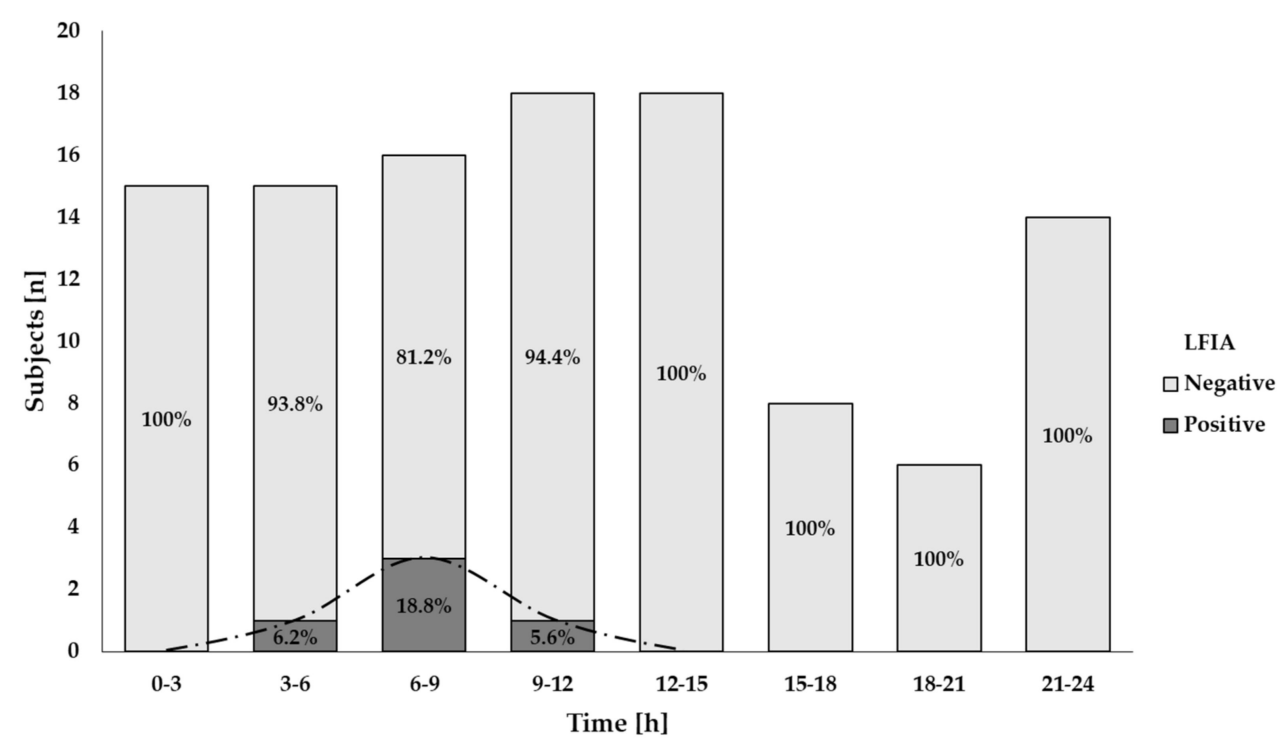

Figure 4. Results of qualitative analysis of GIP excretion in urine after $50 \mathrm{mg}$ of gluten ingestion using a LFIA test. The trend of the GIP detection dynamics is represented by the dashed line. 
Table 1. Individual characteristics of GIP excretion in urine within $24 \mathrm{~h}$ after $50 \mathrm{mg}$ and $2 \mathrm{~g}$ gluten ingestions.

\begin{tabular}{|c|c|c|c|c|c|c|c|c|c|c|c|c|c|c|}
\hline \multicolumn{15}{|c|}{ Urine GIP Excretion in $24 \mathrm{~h}$} \\
\hline \multirow[b]{2}{*}{ Participant } & \multicolumn{7}{|c|}{50 mg Gluten } & \multicolumn{7}{|c|}{$2 \mathrm{~g}$ Gluten } \\
\hline & Samples & LFIA+ & Time Median & Time Range & Peak Max GIP & GIP Median & GIP Range & Samples & LFIA+ & Time Median & Time Range & Peak Max GIP & GIP Median & GIP Range \\
\hline & $n$ & $n$ & h & h & h & $\mathrm{ng} / \mathrm{mL}$ & $\mathrm{ng} / \mathrm{mL}$ & $n$ & $n$ & h & h & h & $\mathrm{ng} / \mathrm{mL}$ & $\mathrm{ng} / \mathrm{mL}$ \\
\hline 1 & 7 & 0 & & & & & & 6 & 1 & 4.50 & $0.00(4.50)$ & 4.50 & 1.80 & $0.00(1.80)$ \\
\hline 2 & 7 & 0 & & & & & & 8 & 6 & 6.00 & $5.00(4.00-9.00)$ & 5.00 & 9.10 & $13.23(2.93-16.17)$ \\
\hline 3 & 4 & 0 & & & & & & 6 & 3 & 7.88 & $3.25(6.25-9.50)$ & 9.50 & 2.20 & $0.80(1.80-2.60)$ \\
\hline 4 & 8 & 0 & & & & & & 9 & 4 & 8.54 & $6.50(5.50-12.00)$ & 7.00 & 3.50 & $5.43(2.30-7.73)$ \\
\hline 5 & 6 & 0 & & & & & & 4 & 1 & 14.67 & $0.00(14.67)$ & 14.67 & 2.50 & $0.00(2.50)$ \\
\hline 6 & 4 & 1 & 3.33 & $0.00(3.33)$ & 3.33 & 4.40 & $0.00(4.40)$ & 4 & 3 & 6.33 & $5.00(3.83-8.83)$ & 8.83 & 4.92 & $5.63(2.10-7.73)$ \\
\hline 8 & 10 & 0 & & & & & & 10 & 5 & 7.67 & $3.00(7.00-10.00)$ & 7.00 & 4.17 & $4.60(2.77-7.37)$ \\
\hline 9 & 7 & 0 & & & & & & 7 & 3 & 6.00 & $2.33(5.00-7.33)$ & 6.00 & 3.47 & $2.40(2.20-4.60)$ \\
\hline 10 & 10 & 0 & & & & & & 7 & 4 & 7.96 & $8.75(6.00-14.75)$ & 6.00 & 6.50 & $11.43(1.77-13.20)$ \\
\hline 11 & 6 & 0 & & & & & & 7 & 2 & 3.21 & $3.42(1.50-4.92)$ & 1.50 & 1.92 & $0.37(1.73-2.10)$ \\
\hline 12 & 6 & 2 & 8.29 & $\begin{array}{c}2.42 \\
(708-950)\end{array}$ & 7.08 & 2.69 & $\begin{array}{c}0.23 \\
(257-280)\end{array}$ & 5 & 2 & 9.04 & $5.92(6.08-12.00)$ & 6.08 & 4.60 & $2.47(3.37-5.83)$ \\
\hline 13 & 5 & 0 & & & & & & 7 & 1 & 7.83 & $0.00(7.83)$ & 7.83 & 1.95 & $0.00(1.95)$ \\
\hline 14 & 5 & 0 & & & & & & 3 & 0 & & & & & \\
\hline 16 & 7 & 0 & & & & & & 10 & 1 & 8.00 & $0.00(8.00)$ & 8.00 & 3.23 & $0.00(3.23)$ \\
\hline 17 & 10 & 0 & & & & & & 10 & 2 & $\begin{array}{l}7.00 \\
7.50\end{array}$ & $0.00(7.50)$ & $\begin{array}{l}7.00 \\
7.50\end{array}$ & 2.60 & $0.00(2.60)$ \\
\hline 19 & 7 & 0 & & & & & & 5 & 2 & 6.32 & $1.97(5.33-7.30)$ & 5.33 & 3.07 & $2.73(1.70-4.43)$ \\
\hline 21 & 8 & 0 & & & & & & 8 & 4 & 8.04 & $7.07(4.42-11.48)$ & 4.42 & 3.12 & $5.53(1.73-7.27)$ \\
\hline 22 & 5 & 1 & 7.67 & $0.00(7.67)$ & 7.67 & 2.30 & $0.00(2.30)$ & 8 & 1 & 5.13 & $0.00(5.13)$ & 5.13 & 1.70 & $0.00(1.70)$ \\
\hline TOTAL & 7 & 0 & 7.67 & $0(3.33-9.50)$ & 7,08 & 2.57 & $\begin{array}{c}2.20 \\
(2.20-4.40)\end{array}$ & 7 & 2 & 7.00 & $13.25(1.50-14.75)$ & 6,54 & 2.68 & $14.83(1.33-16.17)$ \\
\hline
\end{tabular}

GIP: gluten immunogenic peptides; LFIA: lateral flow immunoassay. 


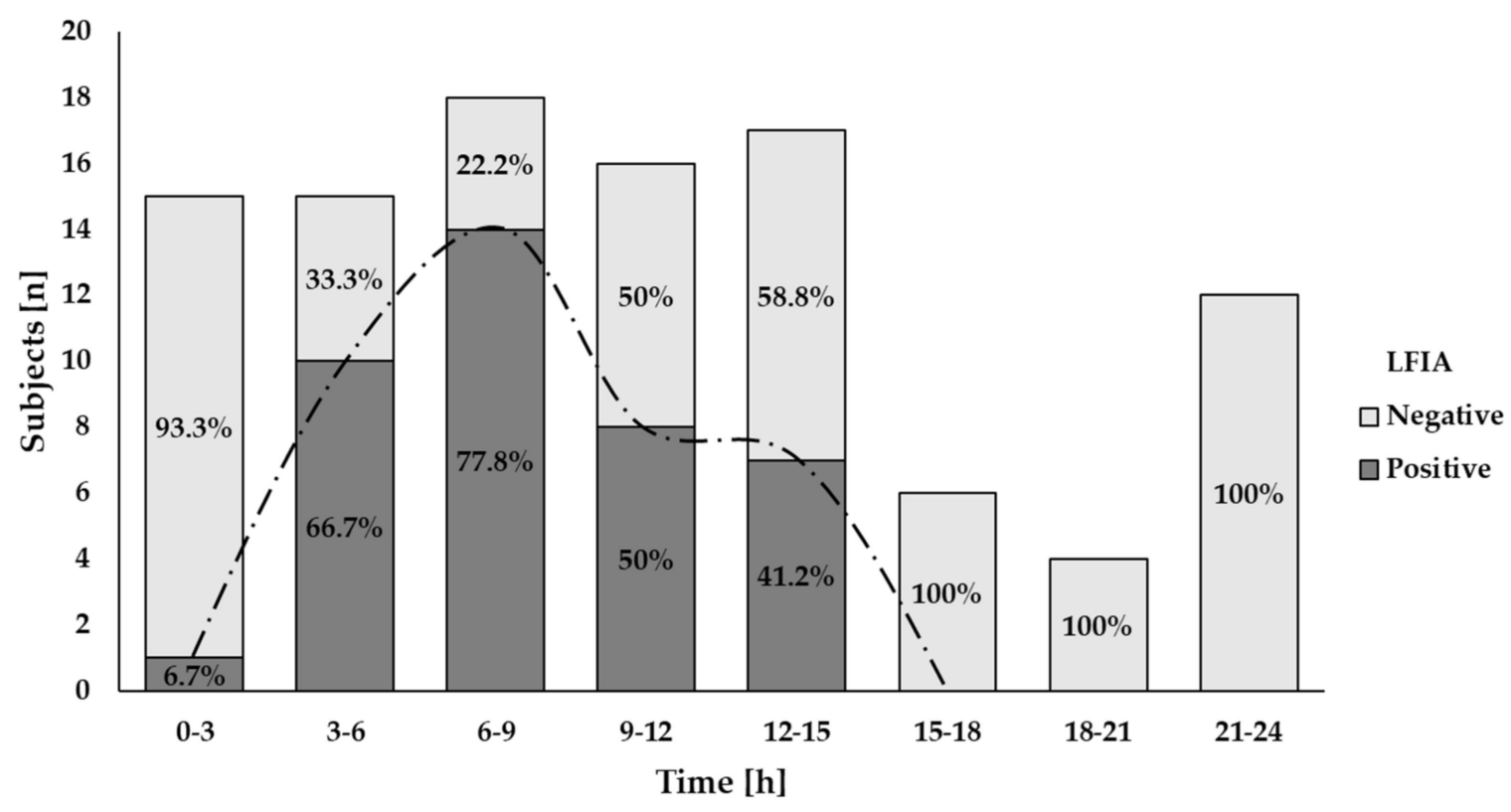

Figure 5. Results of qualitative analysis of GIP excretion in urine after $2 \mathrm{~g}$ of gluten ingestion using a LFIA test. The trend of the GIP detection dynamics is represented by the dashed line.

Despite the variability observed among individuals, both gluten ingestions showed a comparable period for initial GIP detection (7.1 h (range 3.3-7.7)) for the $50 \mathrm{mg}$ dose and $5.8 \mathrm{~h}$ (range 1.5-14.7) for the $2 \mathrm{~g}$ dose) $(p=0.285)$. A longer range of time for detectable GIP per participant was found in the larger gluten dose (0 (range 0-2.4) vs. 3.1 (range 0-8.8)) but without statistical significance $(p=0.180)$.

\subsection{GIP Quantification in Urine}

In line with the time for GIP detection after gluten ingestion, higher concentrations of GIP were measured in the urine of most participants in the same period (6-9 $\mathrm{h}$ ) using an LFIA reader. The median of GIP in this period was $0 \mathrm{ng}$ GIP $/ \mathrm{mL}$ urine (range $0-2.8$ ) for the $50 \mathrm{mg}$ dose and $2.57 \mathrm{ng} \mathrm{GIP} / \mathrm{mL}$ urine (range 0-13.2) for the $2 \mathrm{~g}$ intake (Figure 6, Table 2).

Table 2. Urine GIP detection in 3-hour periods after $50 \mathrm{mg}$ and $2 \mathrm{~g}$ of gluten intakes.

\begin{tabular}{ccccccc}
\hline & \multicolumn{3}{c}{$\mathbf{5 0}$ mg Gluten } & & \multicolumn{2}{c}{ g Gluten } \\
\hline Time & Participants & GIP+ Participants & GIP [ng/mL] & Participants & GIP+ Participants & GIP [ng/mL] \\
\hline h & $\boldsymbol{n}$ & $\boldsymbol{n}$ & Median (Range) & $\boldsymbol{n}$ & $\boldsymbol{n}$ & Median (Range) \\
\hline $0-3$ & 15 & 0 & $0.00(0)$ & 15 & 1 & $0.00(0-2.10)$ \\
$3-6$ & 15 & 1 & $0.00(0-4.40)$ & 15 & 10 & $1.70(0-16.17)$ \\
$6-9$ & 16 & 3 & $0.00(0-2.80)$ & 18 & 8 & $2.57(0-13.20)$ \\
$9-12$ & 18 & 1 & $0.00(0-2.57)$ & 16 & 7 & $0.00(0-4.83)$ \\
$12-15$ & 18 & 0 & $0.00(0)$ & 17 & 0 & $0.00(0-3.37)$ \\
$15-18$ & 8 & 0 & $0.00(0)$ & 6 & 0 & $0.00(0)$ \\
$18-21$ & 6 & 0 & $0.00(0)$ & 4 & 0 & $0.00(0)$ \\
$21-24$ & 14 & 0 & $0.00(0)$ & 12 & $0.00(0)$ \\
\hline
\end{tabular}




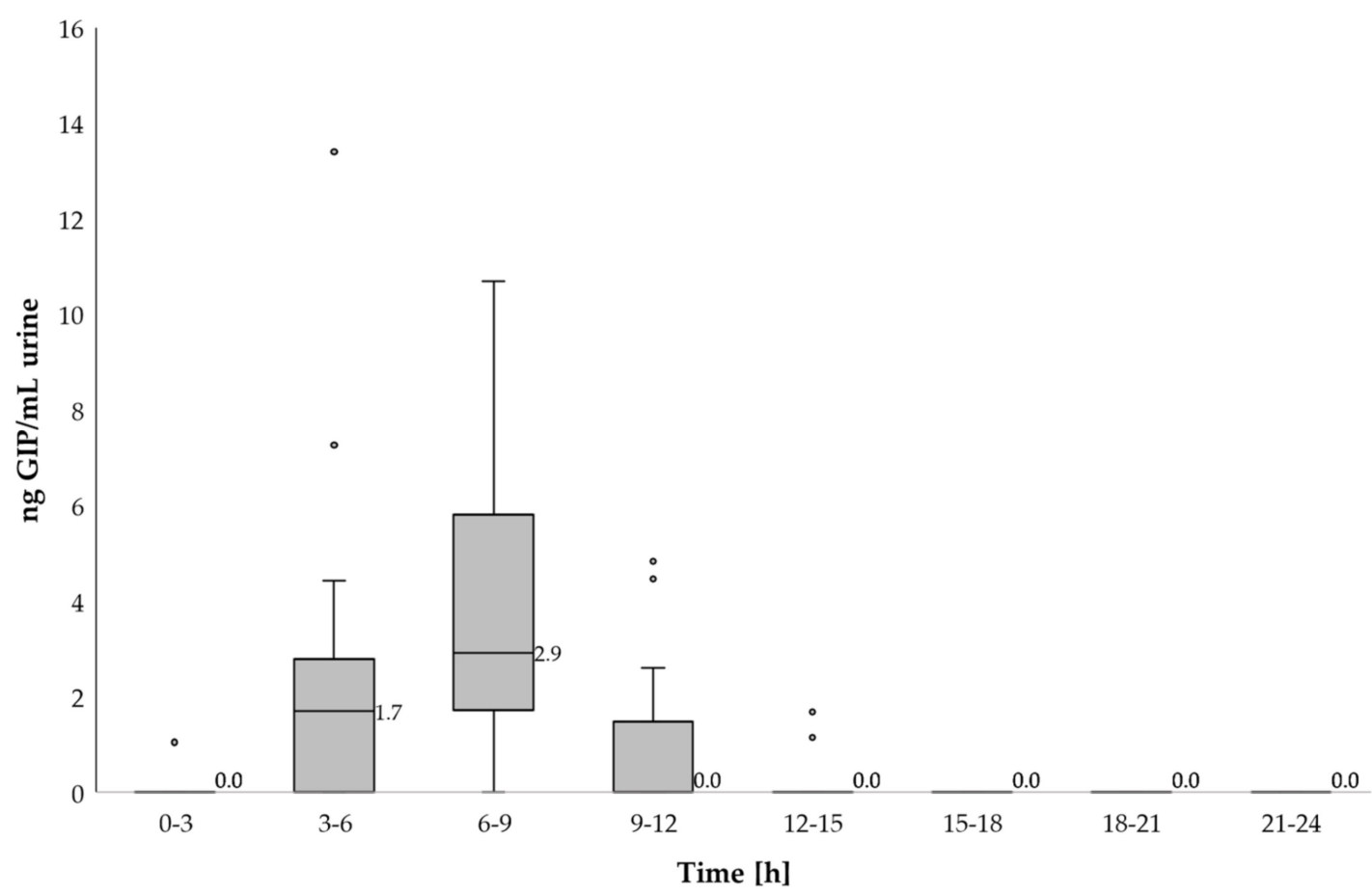

Figure 6. Dynamic of GIP excretion in urine after $2 \mathrm{~g}$ of gluten intake using a LFIA reader. Potential outliers are represented as dots.

However, the peak levels of GIP in urine were observed at different time periods; for the $50 \mathrm{mg}$ dose, it was $4.4 \mathrm{ng} \mathrm{GIP} / \mathrm{mL}$, detected $3.3 \mathrm{~h}$ post ingestion and for the $2 \mathrm{~g}$ dose it was $16.17 \mathrm{ng} \mathrm{GIP} / \mathrm{mL}$, detected $5 \mathrm{~h}$ after gluten ingestion. Considering the period of GIP detection after both gluten doses (3-12 h) the median of GIP was $0 \mathrm{ng}$ GIP/mL urine (range $0-4.4$ ) for the $50 \mathrm{mg}$ dose and $1.73 \mathrm{ng} \mathrm{GIP} / \mathrm{mL}$ urine (range $0-16.17$ ) for the $2 \mathrm{~g}$ intake with statistical differences between ingestions $(p<0.001)$ (Figure 7).

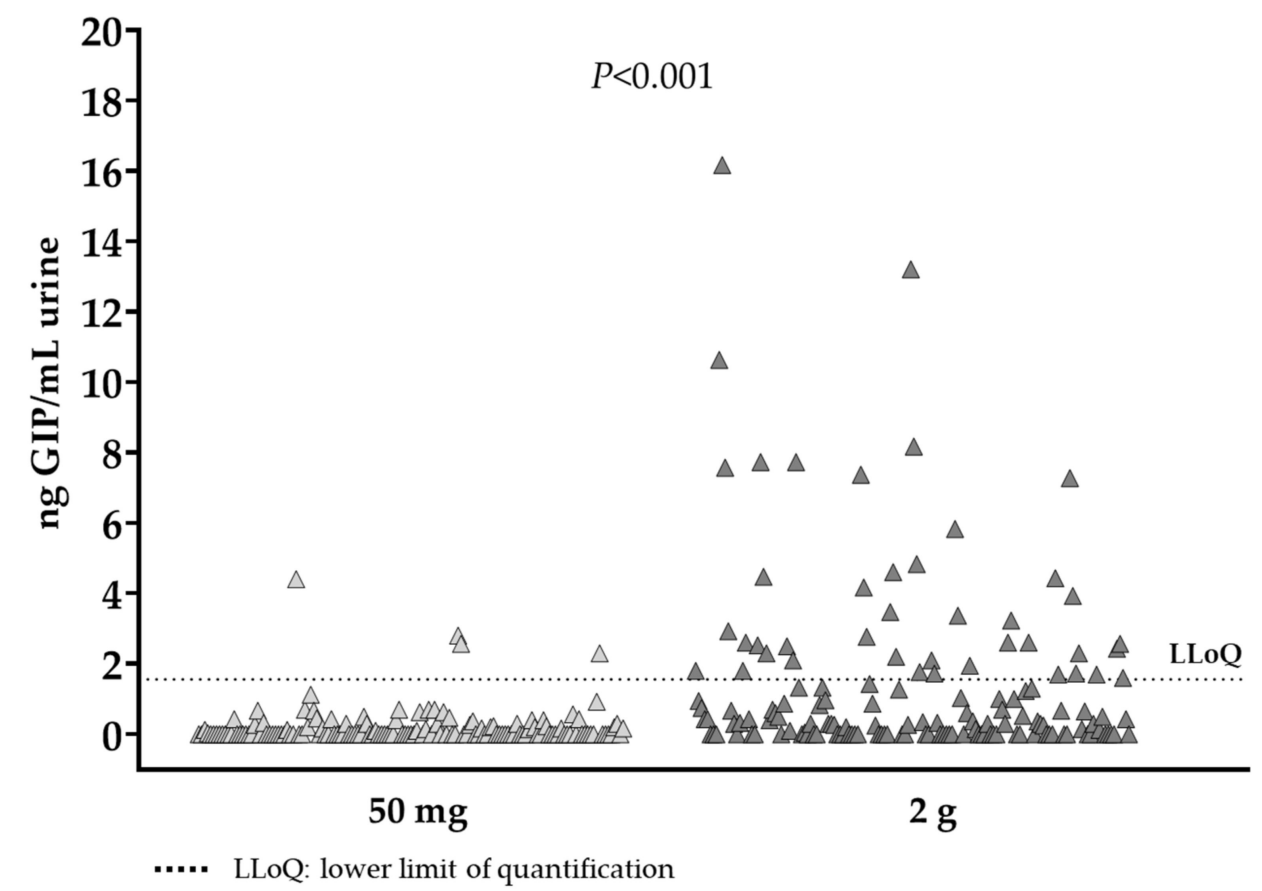

Figure 7. GIP detected in urine samples within $24 \mathrm{~h}$ after $50 \mathrm{mg}$ and $2 \mathrm{~g}$ gluten ingestions. 
We observed a significant negative correlation between the liquid consumption $12 \mathrm{~h}$ after gluten consumption and the levels of GIP in urine detected using an LFIA reader in the same period (rho $=-0.79,95 \%$ CI $[-0.91,-0.53] ; p<0.001$ ) (Figure 8). In contrast, no correlations were found between liquid consumption and urination frequency $($ rho $=0.119,95 \% \mathrm{CI}[-0.34,0.53] ; p=0.62)$ and GIP concentrations and urination frequency (rho $=-0.004,95 \%$ CI $[-0.45,0.44] ; p=0.99)$.

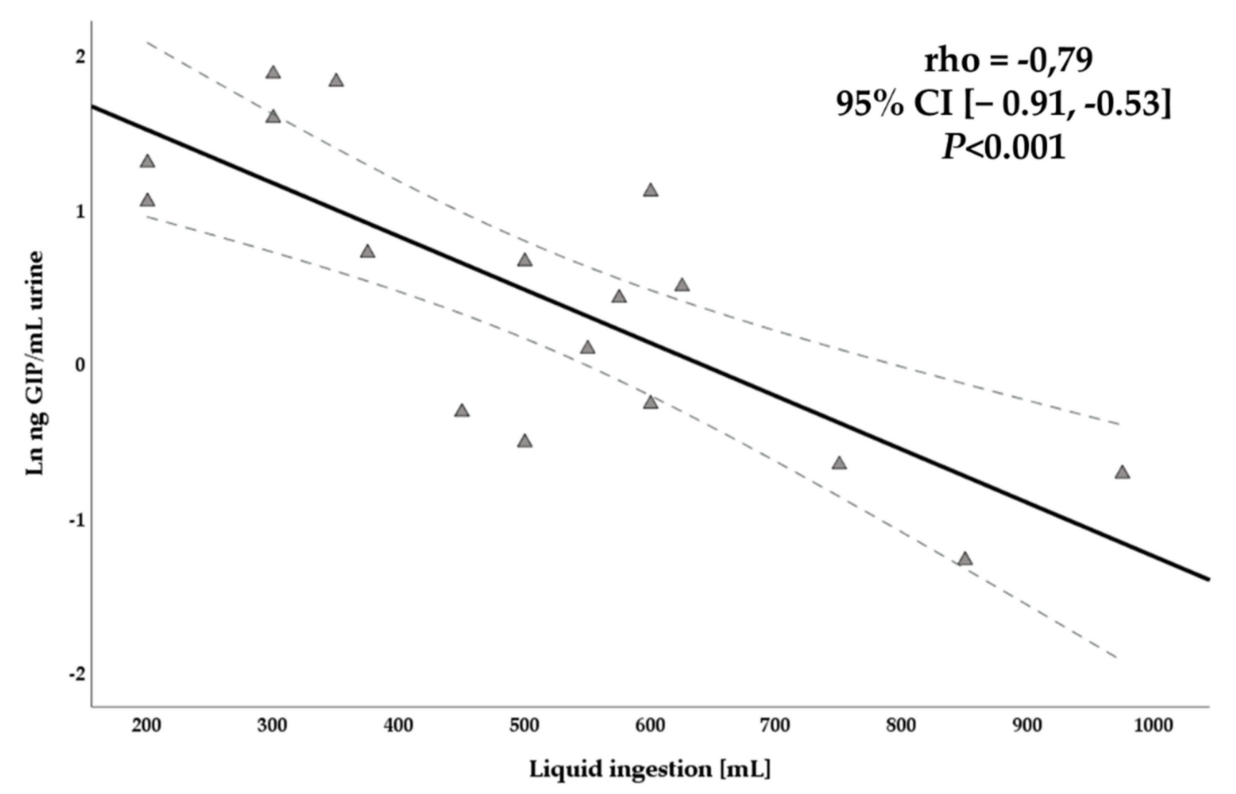

Figure 8. Scatterplot of liquid consumption after $12 \mathrm{~h}$ gluten intake and GIP concentration in urine using a LFIA reader.

\subsection{Interindividual Variability in GIP Excretion}

Despite the limited period of GIP detection in urine after gluten intake, differences in GIP excretion were observed among individuals. Regarding the $50 \mathrm{mg}$ gluten dose, one of three participants reached the peak of GIP concentrations in urine in the first $6 \mathrm{~h}$ post ingestion and two of three participants between 6 and $9 \mathrm{~h}$ post ingestion. Regarding the $2 \mathrm{~g}$ gluten dose, $6 / 20(30 \%)$ participants reached the peak of GIP detection in the range of $0-6 \mathrm{~h}, 9 / 20(45 \%)$ in the range of $6-9 \mathrm{~h}$ and $3 / 20(15 \%)$ after $9 \mathrm{~h}$ post gluten ingestion (Figure 9). Although there were differences in GIP concentrations, GIP excretion patterns were similar in the participants with measurable excreted GIP after both gluten intakes. However, one participant (subject 6) obtained the peak of GIP concentration in the $2 \mathrm{~g}$ dose approximately $6 \mathrm{~h}$ later than the $50 \mathrm{mg}$ dose. In general, no unusual patterns were observed, as most individuals showed a GIP elevation ( $3-9 \mathrm{~h}$ after gluten intake) followed by a decreasing tendency.

When the results were compared between sex, the higher GIP concentrations were seen in the group of females in both gluten intakes, however no statistical significance was observed between females and males in GIP detection $(4.40 \mathrm{ng} / \mathrm{mL}$ vs. $2.50 \mathrm{ng} / \mathrm{mL}$, respectively, for the $50 \mathrm{mg}$ dose $(p=0.319) ; 2.69 \mathrm{ng} / \mathrm{mL}$ vs. $3.12 \mathrm{ng} / \mathrm{mL}$, respectively, for the $2 \mathrm{~g}$ dose $(p=0.162))$. Moreover, similar results were found between groups in terms of initial time of GIP detection ( $3.3 \mathrm{~h}$ vs. $7.38 \mathrm{~h}$, respectively, for the $50 \mathrm{mg}$ dose $(p=0.221$ ); $6.22 \mathrm{~h}$ vs. $5.59 \mathrm{~h}$, respectively, for the $2 \mathrm{~g}$ dose $(p=0.730))$ and time range of GIP detection ( $0 \mathrm{~h}$ vs. $1.21 \mathrm{~h}$, respectively, for the $50 \mathrm{mg}$ dose $(p=0.480) ; 2.90 \mathrm{~h}$ vs. $3.59 \mathrm{~h}$, respectively, for the $2 \mathrm{~g}$ dose $(p=0.688))$. 


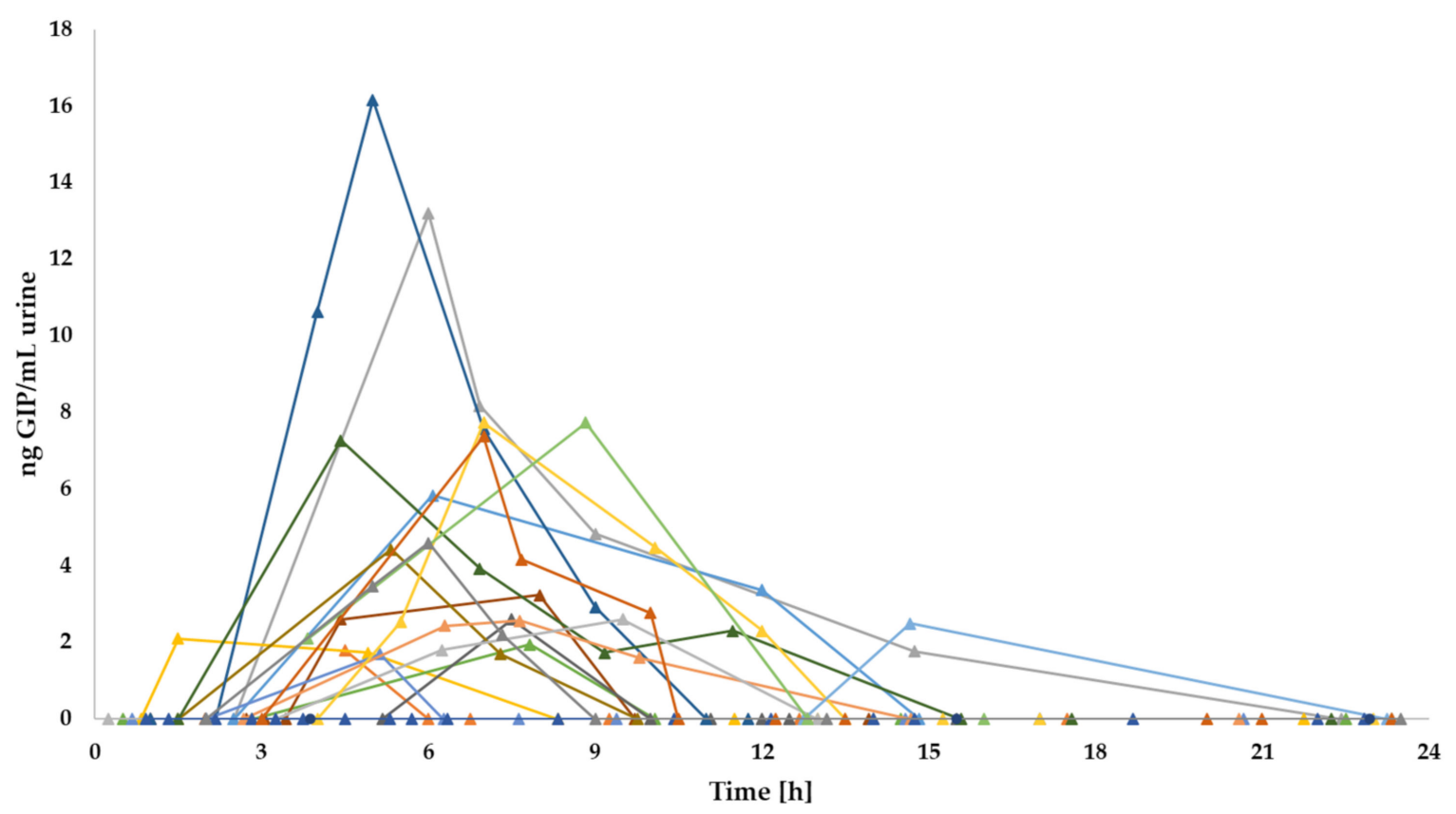

Figure 9. Individual GIP excretion patterns in urine after $2 \mathrm{~g}$ gluten ingestion.

\subsection{Diagnostic Sensitivity of the LFIA Test}

The LFIA test in urine samples demonstrated the capacity for GIP detection after a low gluten ingestion $(50 \mathrm{mg})$. However, this amount of gluten was only detected in 3 out of 20 subjects (15\%). In contrast, with a dose of $2 \mathrm{~g}$ of gluten, the sensitivity of the test increased to $95 \%$ of participants $(19 / 20)$.

The theoretical probability of finding at least one GIP+ result for a single gluten ingestion was calculated considering the interval of time for GIP detection in both amounts of gluten, 3-12 $\mathrm{h}$ after ingestion (Table 3). The diagnostic sensitivity of the LFIA test to detect GIP in a unique urine sample from a small amount of gluten $(50 \mathrm{mg})$ is $7 \%$, which may increase to $13.5 \%$ when two samples are collected and to $19.6 \%$ in three samples collected. In the hypothetical situation of frequent gluten ingestion (i.e., $2 \mathrm{~g}$ ), the sensitivity in a single sample may be $59 \%$, reaching rates of $83.2 \%$ and $93.1 \%$ when two and three samples are collected, respectively.

Table 3. Estimated diagnostic sensitivity of the methods in a specific range of time and with different sample collections.

\begin{tabular}{cccc}
\hline \multicolumn{5}{c}{ LFIA Sensitivity in Urine } \\
\hline \multicolumn{4}{c}{ 50 mg Gluten/2 g Gluten } \\
\hline Time (h) & 1 Sample (\%) & 2 Samples (\%) & 3 Samples (\%) \\
\hline $3-6$ & $6 / 47.8$ & $11.6 / 72.8$ & $16.9 / 85.8$ \\
$6-9$ & $13 / 72$ & $24.3 / 92.2$ & $34.1 / 97.8$ \\
$9-12$ & $4 / 57.1$ & $7.8 / 81.6$ & $11.5 / 92.1$ \\
\hline $3-12$ & $7 / 59$ & $13.5 / 83.2$ & $19.6 / 93.1$ \\
\hline
\end{tabular}

\section{Discussion}

In the present study, we described the dynamics of excretion of GIP in urine samples of healthy subjects who ingested two small doses of gluten under controlled dietary conditions using an immunoassay method based on the anti-33-mer antibodies, G12 and A1 [23,31]. Our results confirmed that the LFIA test could detect a single ingestion of $50 \mathrm{mg}$ of gluten in urine samples collected in a range of 3-10 $\mathrm{h}$ post ingestion, with most GIP excreted in a unique sample per participant. Equivalent results were obtained when the gluten ingestion 
was 40 times higher $(2 \mathrm{~g})$. GIP were detected for this gluten dose in the range of $1-15 \mathrm{~h}$, with most of them obtained between 6 and $9 \mathrm{~h}$ post gluten ingestion.

Consistent with our data, Moreno et al. [23] were the first to demonstrate that the same LFIA method could detect the ingestion of $25 \mathrm{mg}$ and $50 \mathrm{mg}$ of gluten from processed bread in the urine of healthy volunteers. Their results revealed that GIP from those gluten doses were detectable 3-9 $\mathrm{h}$ post ingestion; however, the time of GIP disappearance after a normal gluten-containing diet was extended to 16-34 h compared to this study. They estimated that the time of excretion of gluten-derived peptides ranged from 1 to 2 days. In agreement with these data, other authors found an association between confirmed gluten exposure and GIP presence in urine within $36 \mathrm{~h}$ after ingestion in patients with $\mathrm{CD}[26,27]$. Although the results exhibited a high interindividual variability, the interval between gluten consumption and GIP detection in urine was generally consistent, ranging from $<4$ to $>24 \mathrm{~h}$. Our results with more participants $(n=20)$ showed GIP detection in the first $15 \mathrm{~h}$ after the $2 \mathrm{~g}$ gluten challenge. Thus, depending on the amount of gluten consumed, the period of GIP detection may vary, with a positive trend between gluten consumption and GIP excretion. Nonetheless, it seems that the interval of time between 3 and $9 \mathrm{~h}$ post ingestion may be crucial for GIP detection, independent of the magnitude of gluten exposure. In any case, disagreement in the period to excrete all GIP could also vary depending on the type of ingested gluten, for instance, capsulated gluten in this study vs. other alternatives such as cookies, bread, or cereal bars that have been used in other studies $[23,26,27]$.

Regarding the GIP concentration in urine, we found a significant variation in GIP content of samples collected $24 \mathrm{~h}$ after ingestion of $50 \mathrm{mg}$ and $2 \mathrm{~g}$ gluten $(p<0.001)$. In this study, we observed that the higher the amount of gluten consumed, the more frequent GIP detection and quantification in urine. Nevertheless, interindividual variability was observed, with GIP medians of participants ranging from $2.3-4.4 \mathrm{ng} / \mathrm{g}$ for the $50 \mathrm{mg}$ dose and from $1.7-9.1 \mathrm{ng} / \mathrm{g}$ for the $2 \mathrm{~g}$ dose. The study carried out by Moreno et al. [23] also showed slightly less differences in the maximum GIP content in urine collected after 25 and $50 \mathrm{mg}$ of gluten ingestion (10-15 ng/mL vs. $15-20 \mathrm{ng} / \mathrm{mL}$, respectively), however they pretreat the urine sample with solid phase extraction. Deviations between our results and those from previous studies could be due to the matrix containing the gluten used in the study and the methodology used for GIP quantification.

The correlation between the amount of gluten consumed and the excretion of glutenderived peptides has been previously described [11,23,26,27]. Generally, urine samples from healthy subjects under a normal gluten-containing diet showed a higher amount of GIP than in diet transgressions made by patients with CD. Indeed, most urine samples from these patients were detectable but were under the limit of quantitation $[11,23,26,27]$. Moreno et al. [23] reported GIP quantifications ranging from 6.5 to $600 \mathrm{ng} / \mathrm{mL}$ and 6.5 to $370 \mathrm{ng} / \mathrm{mL}$ in healthy adults and children, respectively, whereas GIP content in urines from patients with CD ranged from 9.27 to $78.12 \mathrm{ng} \mathrm{GIP} / \mathrm{mL}$ and from 9.33 to $29.78 \mathrm{ng} \mathrm{GIP} / \mathrm{mL}$ (in adults and children, respectively). Other authors reported significant differences in urine GIP concentrations between patients with CD under a GFD and de novo CD-diagnosed patients (average range $40.26 \mathrm{ng} / \mathrm{mL}$ vs. $80.31 \mathrm{ng} / \mathrm{mL}, p<0.001$ ) [11].

Although gluten consumption and diet composition were controlled in our study, urinary GIP excretion varied among participants. Urine composition can vary between individuals due to differences in biological factors, body size, physical exercise, environmental conditions, and fluid, salt, and high protein ingestion [32]. Moreover, the sample collection timing in relation to exposure, variation in the kinetics of elimination within and between individuals, and physicochemical properties of the urine matrix should be considered [33]. Hydration status plays a crucial role in variations in the urinary flow rate (volume of urine produced per unit time), and therefore in the concentrations of the biomarker in the study [33]. Although the mechanisms of GIP elimination in urine are currently unknown, our results showed a significant inverse correlation between liquid consumption and GIP concentration in urine $(p<0.001)$, as expected for a higher dilution of 
the urine peptides. However, we did not find a correlation between the urination frequency and GIP concentrations. Thus, it seems that urinary GIP detection may be affected by the amount of liquid ingested. On the other hand, some individuals may not absorb and excrete sufficient GIP in urine to be detected or a fraction of the absorbed GIP might go back to the portal circulation after their pass through the kidneys. Despite one of the participants of the present study obtaining negative results in all the urine samples collected after the $2 \mathrm{~g}$ gluten ingestion, GIP were significantly found in the stools coming from the same period, confirming the gluten exposure (data published separately). Another explanation could be that this participant missed the collection of one or more samples due to the tedious methodology employed in the study.

In a real-life scenario, following a strict GFD is a difficult task for patients with CD. Gluten is reported to be present in a significant percentage of foodstuffs [34]. Consequently, the frequency of diet transgressions is considerable, despite the assumed efforts of the patients $[11,13,26,27,35]$. Furthermore, it was suggested that inadvertent gluten ingestion may be more recurrent than intentional intake, not only when eating out, but also at home $[12,26,27]$. The main goal of this study was to comprehensively determine the pattern of GIP excretion in urine related to a single ingestion of a low amount of gluten, which is the expected situation for inadvertent-involuntary gluten exposure. This information will be valuable in providing more accurate guidance for the use of the GIP tests in patients with CD. On the basis of these results, future studies with the target population may build an effective protocol for urine sample collection to establish the algorithm of assessment of GFD adherence.

On the other hand, a recent publication with a cohort of 77 participants under a GFD for $\geq 2$ years revealed that the urine LFIA test obtained a diagnostic sensitivity of $94.4 \%$ and negative predictive value of $96.9 \%$ in detecting mucosal damage when urine samples were collected on three different days, two of them over the weekend [11]. Other authors reported a rate of $69.8 \%$ of patients with at least one GIP+ in urine when they collected weekly samples on weekends over 4 weeks [13]. Thus, considering the short period of GIP detection in urine (3-12 h) after gluten intake and the variability in GIP excretion within and between individuals in our study, it seems that the increase in the frequency of tests may be a worthwhile approach to reduce the probability of false negative results due to punctual gluten consumptions [11,13]. In this scenario, the use of three LFIA tests in urine collected at different times during weekdays and weekends may reach a sensitivity of $19.6 \%$ for very low gluten intakes, such as $50 \mathrm{mg}$, while this sensitivity could increase to 93.1\% with higher gluten exposures, such as $2 \mathrm{~g}$.

Regarding the optimum time for urine collection, several circumstances need to be considered, such as the period with a higher rate of GIP detection: 3-12 h post ingestion, meals with a greater chance of gluten exposure (lunch and dinner), and the best time to obtain a concentrated urine sample in most individuals. Hence, it seems that the last urine in the night, or alternatively the first one in the morning, would meet most of these conditions. Routinely, first-morning urine samples are required for urinary analysis as a representative sample of the average urine of the day and because they have the highest concentration of peptides [33]. However, food ingestion occurs during the day, therefore, depending on the dynamics of excretion, analyte detection among subjects could fluctuate [33]. Alternations of first-morning urine and the last urine in the day may offer more probabilities to reveal a diet transgression made at lunch and dinner times. Moreno et al. [23] suggested the collection of 24-h total urine to increase the probability of GIP detection from a low amount of gluten ingestion; however, the complexity for patients is higher and urine samples with detectable amounts of GIP could be diluted, decreasing the concentration of the final sample.

The main limitations of this study were the inclusion of only healthy volunteers, and that maybe the sample size could be increased. The complexity of the study design, requiring a big effort from the volunteers, and the declaration of the COVID-19 pandemic make the recruitment process a difficult task. Furthermore, the inclusion of patients 
with CD had ethical concerns. Although it is generally believed that gluten metabolism is similar between patients with CD and healthy subjects, several aspects need to be addressed when the $\mathrm{CD}$ population is considered as they may present digestive alterations, intestinal permeability, and differences in the microbiota involved in the gluten degradation process $[21,36,37]$. In fact, it was described that patients with CD may have a higher proteolytic activity in the intestine leading to a gluten reduction in feces in comparison to healthy subjects and first-degree relatives on normal diet [37]. Moreover, a recent study confirmed that patients with $C D$ consuming wheat excreted in urine a significantly higher diversity of gluten-derived peptides than healthy subjects, however differences the healing of the intestinal epithelia between patients with CD were not contemplated [28]. Thus, since the test for GIP detection in urine is intended for use by people suffering from CD and gluten-related disorders, future studies with these populations with similar gluten consumptions will confirm the compatibility of our results for the definition of clinical practice guidelines for the application of GIP in the monitoring of GFD.

The ability to capture a biomarker in a sample of urine is a noninvasive procedure that is convenient for almost all population [33]. Therefore, urinary GIP detection provides a supplemental tool to evaluate gluten exposure in individuals following a GFD. In conclusion, the results of this study will provide additional knowledge about gluten metabolism and GIP excretion, which could be useful to fine-tune the application of GIP determination in the follow-up of patients with CD and gluten-related disorders.

Author Contributions: Conceptualization, L.C. and A.C.; Data curation, L.C.; Formal analysis, L.C.; Investigation, L.C.; Project administration, A.C.; Resources, A.C.; Supervision, C.S. and A.C.; Validation, C.S. and A.C.; Writing-original draft, L.C.; Writing-review \& editing, C.S. and A.C. All authors have read and agreed to the published version of the manuscript.

Funding: This work was supported by grants from Ministerio de Ciencia e Innovación (DI-16-08943) and Junta de Andalucía, Consejería de Economía, Conocimiento, Empresas y Universidad and FEDER funds (AT17_5489_USE). We also thank the generous volunteer subjects who enrolled in the study.

Institutional Review Board Statement: The study was conducted according to the guidelines of the Declaration of Helsinki, and approved by the Ethics Committee of Virgen del Rocío and Virgen Macarena University Hospitals (n. 2381-N-19; 03/02/2020).

Informed Consent Statement: Informed consent was obtained from all subjects involved in the study.

Acknowledgments: This paper will be part of the Laura Coto's doctorate that it is being carried out within the context of "Human Nutrition Program" at the University of Granada. She was supported by a Research Fellowship from the Government of Spain (DI-16-08943).

Conflicts of Interest: Angel Cebolla is the founder and current CEO of Biomedal S.L. (Seville, Spain), Angel Cebolla and Carolina Sousa are inventors of the patent "Detecting gluten peptides in human fluids" (no. WO/2016/005643), and Laura Coto is employee at Biomedal S.L.

\section{References}

1. Lindfors, K.; Ciacci, C.; Kurppa, K.; Lundin, K.E.A.; Makharia, G.K.; Mearin, M.L.; Murray, J.A.; Verdu, E.F.; Kaukinen, K. Coeliac Disease. Nat. Rev. Dis. Prim. 2019, 5, 3. [CrossRef]

2. Fasano, A.; Catassi, C. Celiac Disease. N. Engl. J. Med. 2012, 367, 2419-2426. [CrossRef]

3. Caio, G.; Volta, U.; Sapone, A.; Leffler, D.A.; De Giorgio, R.; Catassi, C.; Fasano, A. Celiac Disease: A Comprehensive Current Review. BMC Med. 2019, 17, 142. [CrossRef] [PubMed]

4. Abadie, V.; Sollid, L.M.; Barreiro, L.B.; Jabri, B. Integration of Genetic and Immunological Insights into a Model of Celiac Disease Pathogenesis. Annu. Rev. Immunol. 2011, 29, 493-525. [CrossRef]

5. Lebwohl, B.; Sanders, D.S.; Green, P.H.R. Seminar Coeliac Disease. Lancet 2018, 391, 70-81. [CrossRef]

6. Elli, L.; Ferretti, F.; Orlando, S.; Vecchi, M.; Monguzzi, E.; Roncoroni, L.; Schuppan, D. Management of Celiac Disease in Daily Clinical Practice. Eur. J. Intern. Med. 2019, 61, 15-24. [CrossRef]

7. Therrien, A.; Kelly, C.P.; Silvester, J.A. Celiac Disease. J. Clin. Gastroenterol. 2020, 54, 8-21. [CrossRef] [PubMed]

8. Troncone, R.; Auricchio, R.; Granata, V. Issues Related to Gluten-Free Diet in Coeliac Disease. Curr. Opin. Clin. Nutr. Metab. Care 2008, 11, 329-333. [CrossRef] 
9. Hall, N.J.; Rubin, G.; Charnock, A. Systematic Review: Adherence to a Gluten-Free Diet in Adult Patients with Coeliac Disease. Aliment. Pharmacol. Ther. 2009, 30, 315-330. [CrossRef]

10. Villafuerte-Galvez, J.; Vanga, R.R.; Dennis, M.; Hansen, J.; Leffler, D.A.; Kelly, C.P.; Mukherjee, R. Factors Governing Long-Term Adherence to a Gluten-Free Diet in Adult Patients with Coeliac Disease. Aliment. Pharmacol. Ther. 2015, 42, 753-760. [CrossRef]

11. Ruiz-Carnicer, Á.; Garzón-Benavides, M.; Fombuena, B.; Segura, V.; García-Fernández, F.; Sobrino-Rodríguez, S.; GómezIzquierdo, L.; Montes-Cano, M.A.; Rodríguez-Herrera, A.; Millán, R.; et al. Negative Predictive Value of the Repeated Absence of Gluten Immunogenic Peptides in the Urine of Treated Celiac Patients in Predicting Mucosal Healing: New Proposals for Follow-up in Celiac Disease. Am. J. Clin. Nutr. 2020, 112, 1240-1251. [CrossRef]

12. Muhammad, H.; Reeves, S.; Jeanes, Y.M. Identifying and Improving Adherence to the Gluten-Free Diet in People with Coeliac Disease. Proc. Nutr. Soc. 2019, 78, 418-425. [CrossRef]

13. Stefanolo, J.P.; Tálamo, M.; Dodds, S.; de la Paz Temprano, M.; Costa, A.F.; Moreno, M.L.; Pinto-Sánchez, M.I.; Smecuol, E.; Vázquez, H.; Gonzalez, A.; et al. Real-World Gluten Exposure in Patients With Celiac Disease on Gluten-Free Diets, Determined From Gliadin Immunogenic Peptides in Urine and Fecal Samples. Clin. Gastroenterol. Hepatol. 2021, 19, 484-491.e1. [CrossRef]

14. Myléus, A.; Reilly, N.R.; Green, P.H.R. Rate, Risk Factors, and Outcomes of Nonadherence in Pediatric Patients with Celiac Disease: A Systematic Review. Clin. Gastroenterol. Hepatol. 2020, 18, 562-573. [CrossRef]

15. Catassi, C.; Fabiani, E.; Iacono, G.; D’Agate, C.; Francavilla, R.; Biagi, F.; Volta, U.; Accomando, S.; Picarelli, A.; De Vitis, I.; et al. A Prospective, Double-Blind, Placebo-Controlled Trial to Establish a Safe Gluten Threshold for Patients with Celiac Disease. Am. J. Clin. Nutr. 2007, 85, 160-166. [CrossRef] [PubMed]

16. Collin, P.; Thorell, L.; Kaukinen, K.; Mäki, M. The Safe Threshold for Gluten Contamination in Gluten-Free Products. Can Trace Amounts Be Accepted in the Treatment of Coeliac Disease? Aliment. Pharmacol. Ther. 2004, 19, 1277-1283. [CrossRef] [PubMed]

17. Mena, M.C.; Sousa, C. Analytical Tools for Gluten Detection. Policies and Regulation. In Advances in the Understanding of Gluten related Pathology and the Evolution of Gluten-Free Foods; OmniaScience: Terrassa, Spain, 2015; pp. 527-564. [CrossRef]

18. Shewry, P.R.; Halford, N.G.; Belton, P.S.; Tatham, A.S. The Structure and Properties of Gluten: An Elastic Protein from Wheat Grain. Philos. Trans. R. Soc. B Biol. Sci. 2002, 357, 133-142. [CrossRef] [PubMed]

19. Cebolla, Á.; Moreno, M.; Coto, L.; Sousa, C. Gluten Immunogenic Peptides as Standard for the Evaluation of Potential Harmful Prolamin Content in Food and Human Specimen. Nutrients 2018, 10, 1927. [CrossRef] [PubMed]

20. Shan, L. Structural Basis for Gluten Intolerance in Celiac Sprue. Science 2002, 297, 2275-2279. [CrossRef]

21. Caminero, A.; Nistal, E.; Herrán, A.R.; Pérez-Andrés, J.; Vaquero, L.; Vivas, S.; Ruíz de Morales, J.M.; Casqueiro, J. Gluten Metabolism in Humans. In Wheat and Rice in Disease Prevention and Health; Elsevier: Amsterdam, The Netherlands, 2014; pp. 157-170. [CrossRef]

22. Bhutia, Y.D.; Ganapathy, V. Protein Digestion and Absorption. In Physiology of the Gastrointestinal Tract; Elsevier: Amsterdam, The Netherlands, 2018; Volume 2, pp. 1063-1086. [CrossRef]

23. Moreno, M.D.L.; Cebolla, Á.; Muñoz-Suano, A.; Carrillo-Carrion, C.; Comino, I.; Pizarro, Á.; León, F.; Rodríguez-Herrera, A.; Sousa, C. Detection of Gluten Immunogenic Peptides in the Urine of Patients with Coeliac Disease Reveals Transgressions in the Gluten-Free Diet and Incomplete Mucosal Healing. Gut 2017, 66, 250-257. [CrossRef] [PubMed]

24. Costa, A.F.; Sugai, E.; de la Paz Temprano, M.; Niveloni, S.I.; Vázquez, H.; Moreno, M.L.; Domínguez-Flores, M.R.; Muñoz-Suano, A.; Smecuol, E.; Stefanolo, J.P.; et al. Gluten Immunogenic Peptide Excretion Detects Dietary Transgressions in Treated Celiac Disease Patients. World J. Gastroenterol. 2019, 25, 1409-1420. [CrossRef]

25. Lähdeaho, M.-L.; Scheinin, M.; Vuotikka, P.; Taavela, J.; Popp, A.; Laukkarinen, J.; Koffert, J.; Koivurova, O.-P.; Pesu, M.; Kivelä, L.; et al. Safety and Efficacy of AMG 714 in Adults with Coeliac Disease Exposed to Gluten Challenge: A Phase 2a, Randomised, Double-Blind, Placebo-Controlled Study. Lancet Gastroenterol. Hepatol. 2019, 4, 948-959. [CrossRef]

26. Silvester, J.A.; Comino, I.; Rigaux, L.N.; Segura, V.; Green, K.H.; Cebolla, A.; Weiten, D.; Dominguez, R.; Leffler, D.A.; Leon, F.; et al Exposure Sources, Amounts and Time Course of Gluten Ingestion and Excretion in Patients with Coeliac Disease on a Gluten-Free Diet. Aliment. Pharmacol. Ther. 2020, 52, 1469-1479. [CrossRef]

27. Silvester, J.A.; Comino, I.; Kelly, C.P.; Sousa, C.; Duerksen, D.R.; Bernstein, C.N.; Cebolla, A.; Dominguez, M.R.; Graff, L.A.; Green, K.H.; et al. Most Patients With Celiac Disease on Gluten-Free Diets Consume Measurable Amounts of Gluten. Gastroenterology 2020, 158, 1497-1499.e1. [CrossRef] [PubMed]

28. Palanski, B.A.; Weng, N.; Zhang, L.; Hilmer, A.J.; Fall, L.A.; Swaminathan, K.; Jabri, B.; Sousa, C.; Fernandez-becker, N.Q. An Efficient Urine Peptidomics Workflow Identifies Chemically Defined Dietary Gluten Peptides from Patients with Celiac Disease. bioRxiv 2021, 1-23. [CrossRef]

29. Adachi, J.; Kumar, C.; Zhang, Y.; Olsen, J.V.; Mann, M. The Human Urinary Proteome Contains More than 1500 Proteins, Including a Large Proportion of Membrane Proteins. Genome Biol. 2006, 7, R80. [CrossRef] [PubMed]

30. Biagi, F.; Andrealli, A.; Bianchi, P.I.; Marchese, A.; Klersy, C.; Corazza, G.R. A Gluten-Free Diet Score to Evaluate Dietary Compliance in Patients with Coeliac Disease. Br. J. Nutr. 2009, 102, 882-887. [CrossRef]

31. Morón, B.; Bethune, M.T.; Comino, I.; Manyani, H.; Ferragud, M.; López, M.C.; Cebolla, Á.; Khosla, C.; Sousa, C. Toward the Assessment of Food Toxicity for Celiac Patients: Characterization of Monoclonal Antibodies to a Main Immunogenic Gluten Peptide. PLoS ONE 2008, 3, e2294. [CrossRef]

32. Rose, C.; Parker, A.; Jefferson, B.; Cartmell, E. The Characterization of Feces and Urine: A Review of the Literature to Inform Advanced Treatment Technology. Crit. Rev. Environ. Sci. Technol. 2015, 45, 1827-1879. [CrossRef] 
33. Aylward, L.L.; Hays, S.M.; Smolders, R.; Koch, H.M.; Cocker, J.; Jones, K.; Warren, N.; Levy, L.; Bevan, R. Sources of Varia-bility in Biomarker Concentrations. J. Toxicol. Environ. Health B Crit. Rev. 2014, 17, 45-61. [CrossRef]

34. Lerner, B.A.; Phan Vo, L.T.; Yates, S.; Rundle, A.G.; Green, P.H.R.; Lebwohl, B. Detection of Gluten in Gluten-Free Labeled Restaurant Food: Analysis of Crowd-Sourced Data. Am. J. Gastroenterol. 2019, 114, 792-797. [CrossRef]

35. Comino, I.; Fernández-Bañares, F.; Esteve, M.; Ortigosa, L.; Castillejo, G.; Fambuena, B.; Ribes-Koninckx, C.; Sierra, C.; RodríguezHerrera, A.; Salazar, J.C.; et al. Fecal Gluten Peptides Reveal Limitations of Serological Tests and Food Questionnaires for Monitoring Gluten-Free Diet in Celiac Disease Patients. Am. J. Gastroenterol. 2016, 111, 1456-1465. [CrossRef] [PubMed]

36. Ménard, S.; Lebreton, C.; Schumann, M.; Matysiak-Budnik, T.; Dugave, C.; Bouhnik, Y.; Malamut, G.; Cellier, C.; Allez, M.; Crenn, P.; et al. Paracellular versus Transcellular Intestinal Permeability to Gliadin Peptides in Active Celiac Disease. Am. J. Pathol. 2012, 180, 608-615. [CrossRef] [PubMed]

37. Caminero, A.; Nistal, E.; Herrán, A.R.; Pérez-Andrés, J.; Ferrero, M.A.; Vaquero Ayala, L.; Vivas, S.; Ruiz De Morales, J.M.G.; Albillos, S.M.; Casqueiro, F.J. Differences in Gluten Metabolism among Healthy Volunteers, Coeliac Disease Patients and First-Degree Relatives. Br. J. Nutr. 2015, 114, 1157-1167. [CrossRef] [PubMed] 